\title{
Developing a location-inventory-routing model using METRIC approach in inventory policy
}

\author{
Farhad Habibi, Ehsan Asadi and Seyed Jafar Sadjadi*
}

\begin{tabular}{l} 
Department of Industrial Engineering, \\
\hline C H R O N I C L E \\
\hline Article history: \\
Received December 2, 2016 \\
Received in revised format \\
December 10, 2016 \\
Accepted April 142017 \\
Available online \\
April 14 2017 \\
\hline Keywords: \\
LIRP model \\
Integrated supply chain \\
Metric approach \\
Metaheuristic algorithm \\
One-for-one replenishment \\
policy
\end{tabular}

\section{Introduction}

Today, the rapid economic changes and intense competitive pressures in global markets has led companies and organizations to pay more attention to the supply chain management. The organizations and companies which are involved with chain structure will attain greater benefits in the competition. Based on the impact of time horizon, Researchers often divide supply chain decisions into three types of strategic decisions, tactical decisions and operational decisions. Strategic decisions deal with locating the facilities that has significantly longer term influence on the organizations. Tactical decisions deal with inventory management and distribution decisions are considered as the types of the operational decisions with the minimum time period influence. In the past, these decisions were taken separately and this was caused sub-optimality and rising costs. Recently, the researchers found that considering the decisions listed simultaneously in one model, will result in enormous savings (Hiassat \& Diabat, 2011). The main purpose of this study is to optimize the decisions related to distributors' location and allocating retailers to them, determine optimal inventory policy for distributors and * Corresponding author Tel.: +98-2177240129

E-mail address: sjsadjadi@iust.ac.ir (S.J. Sadjadi)

(C) 2017 Growing Science Ltd. All rights reserved. doi: $10.5267 /$ j.uscm.2017.4.003

\begin{abstract}
A B S T R A C T
Locating, routing and inventory control in production and distribution centers are the most mportant decisions in supply chain management. Because of the dependence of these on cost reduction. In this study, first, a location-inventory model is developed by utilizing METRIC approach and then, METRIC approach is applied to the location-inventory-routing model. The intended supply chain includes a supplier, distributors and retailers, and the demand follows Poisson distribution and the lead-time is also considered probabilistic and is affected by the shortage in distribution centers. Given that the presented model belongs to the class of NP-hard problems, a hybrid metaheuristic solution method is also presented to solve the resulted problem. The proposed hybrid metaheuristic algorithm contains a Simulated
Annealing algorithm, to optimize the location-routing problem, and a Genetic Algorithm, to optimize the inventory problem. Also, to evaluate the performance of hybrid algorithm, a comparison between the results of the proposed hybrid algorithm and the exact solutions obtained from Lingo software is provided and, finally, the results are analyzed.
\end{abstract}


retailers and determine the optimal route of serving to retailers, simultaneously; so that the total cost related to location, inventory and transportation is to be minimized.

\section{Literature review}

In the 1980s, organizations were looking for techniques and strategies that they can use to cut production costs and compete in different markets. Hence, the supply chain issue was raised so that costs are reduced through the created potential opportunities. Distribution network as one of the major causes of supply chain costs, affects the chain performance. Therefore, choosing a suitable and integrated distribution network can facilitate the achievement of various targets of supply chain. The members of the supply chain include suppliers, warehouses related to raw materials, production centers, distributors, retailers and final customers and the design of a distribution network contains three major problems of assigning location, vehicle routing and inventory control. In the past two decades, much research has been done to develop an integrated distribution network, mainly focused on integrating two of the above issues. Hence, the location-routing, location-inventory and inventory-routing problems were introduced. Location-Routing Problems (LRP) are one of the oldest integration issues that have been studied since the mid-1970s. This kind of problems was discussed to find the location and suitable number of facilities as well as distribution routs for the vehicles. (See, e.g., Min et al., 1998; Nagy \& Salhi, 2007; Prodhon \& Prins, 2014). Inventory-Routing Problems (IRP), which were considered in the early $1980 \mathrm{~s}$, are related to storage and distribution of products among a set of customers during a specific planning horizon. (See, e.g., Campbell et al., 1998; Bertazzi et al., 2008; Cordeau et al., 2007). Location-Inventory Problems (LIP) include those of the decisions which are related to inventory reserves in facility location problem. These problems have been considered by many researchers during the past decade (Owen \& Daskin, 1998). (See also, e.g., Melo et al., 2009; Farahani et al., 2015).

Location-Inventory-Routing Problems (LIRP) make integrated decisions on facility location, inventory control and materials ordering, and transport routes planning issues. So, we can say that in this category of problems, strategic, tactical and operational decisions are considered simultaneously. Research Liu and Lee (2003) is one of the basic research on LIRP issues where a heuristic method was proposed for solving these types of problems. Then, Liu and Lin (2005) provided a new method to solve the model presented by Liu and Lee (2003) in which, the LIRP problem was divided into the warehouses locationallocation and routing-inventory problems, and then, the final solution was provided by two phases of generating the initial solution and using hybrid solution algorithm of TS and SA. Javid and Azad (2010) have modeled the LIRP problem in the single-product and single-period mode with considering an infinite capacity for suppliers and probabilistic demand for customers that follows the normal distribution. Providing multi-level capacity for each of distribution centers and selecting among them makes this article distinct from the other related articles. Wang et al. (2008) entered reverse logistics issues into the LIRP problems. The closed loop logistics system, considered by them, was a three-level supply chain and includes a plant, several logistics centers and several distribution or collection points. The model provided by them, was a single-product model and has been developed in multi-period mode. Jiang and Ma (2009) have considered the LIRP problem in closed loop logistics systems to collect and recycle the products whose life has expired. Their model assumptions were consistent with the hypotheses of research Wang et al. (2008), and only a two-stage heuristic algorithm based on Genetic Algorithm (GA) has been developed. Nekooghadirli et al. (2014) presented a bi-objective and multi-product model for the LIRP problem where the total cost and maximum average time of delivering products to customers is minimized, simultaneously. Ambrosino and Scutella (2005) have considered the LIRP problem with four layers including the plant, central warehouse, regional warehouses and customers. The aim of their problem was to determine the location and number of different facilities in a new network or to improve an existing network. Seyedhosseini et al. (2014) introduced an integrated model of LIRP to consider the possibility of failure in distribution centers. The model introduced by them, simultaneously determines the distributors' locations that should be open, 
how to allocate customers to distributors and to allocate customers to the active routes, the order of serving products to them in each route, and inventory policy in each distribution center.

Multi-Echelon Technique for Recoverable Item Control (METRIC) approach was firstly introduced by Sherbrooke (1968) to optimize the inventory level of air force spare parts warehouses, where, the time between two demands for repairing or replacing the parts is probabilistic and follows the exponential distribution. He calculated some performance measures using queuing theory theorems to determine the optimal inventory level. After that, Muckstadt (1973) generalized Sherbrooke's METRIC approach, and considered a hierarchical structure for the products. He assumed that when a part needs to be repaired, exactly one of its sub-components (modules) needs repairing. Slay (1984) developed a METRIC model, known as VARI-METRIC, in which the average number of items under repair is equal to its variance and he used the negative binomial distribution for this assumption. Graves (1985) independently used this distribution for proposing exact and approximate methods in a multi-level problem. Afterwards, Sherbrooke (1986) considered a model similar to Muckstadt (1973); however, he used a different approximate approach and with the numerical examples, showed that a significant improvement can be provided in the accuracy of the METRIC method by using his proposed approach. The Sherbrooke's model was later developed as a standard model by researchers and different solution methods were used to solve it. For example, Wang et al. (2000) developed a two-level repairable inventory system where, the lead time for replenishment was considered probabilistic. Rustenburg et al. (2003) developed an exact model for a multi-level problem and then, Wong et al. (2005) developed an analytical model to determine the optimal inventory levels of spare parts in a repairable item inventory system with considering several plants and distributors and assuming the multi-product mode. Andersson and Melehiors (2001) presented a two-level model with a central warehouse and several retailers that customers' demand for the retailers considered probabilistic and follows the Poisson distribution. In their model, all the lead times were fixed and used inventory policy was $(S-1, S)$ with the continuous review. They used METRIC method in their modeling and evaluated the proposed model by using 13 test problems.

In this paper, a LIRP model is presented with considering the METRIC approach to modeling the inventory policy that has the following aspects of innovation compared to the other similar researches:

- Through reviewing the location-inventory-routing problems literature, it can be seen that none of the studies and researches conducted in this field has considered the $(S-1, S)$ inventory policy, although it is known as an important inventory policy. Therefore, in this study, this policy is being used to model the problem.

- Also, in the most studies, the uncertainty in transport time that leads to uncertainty in lead time has not been considered. While in this paper, lead time is considered as a function of shortage.

- In most papers, because of the normal distribution nature and ease of deployment, customers' demand is considered as the function of normal distribution; while the demand can be better approximated using the Poisson distribution. In this paper, retailers' demand follows the Poisson distribution.

- METRIC approach is one of the new approaches to determine the amount of inventory level in the $(S-1, S)$ inventory policy. In this paper, the METRIC approach is used to model the location-inventory and location-inventory-routing problems.

\section{The location-inventory problem with METRIC approach}

\subsection{Problem definition}

The supply chain studied in this paper is consisted of three levels including a supplier, potential distributors and retailers. Also, it is assumed that the locations of supplier and retailers are specified and we aim to determine the number and locations of distributors to meet the retailers' demands. The 
inventory policy intended to hold the inventory at the retailers and distributors comply with $(S-1, S)$ policy and the purpose of the problem is to determine the optimal inventory level for the retailers and distributors, so that the holding and shortage costs will be minimized. Demands of the retailers follow the Poisson process and therefore, the demand of each distributor will be equal to sum of the demands of the retailers which are assigned to that distributor. Lead (Procurement) time to receive the retailers' orders from distributors is the function of the shortage in each distributor and is considered probabilistic. This function is obtained based on queuing theory rules which are described below. In this case, it is assumed that the supplier has no supply capacity constraint. Fig. 1 shows the overall structure of the intended supply chain.

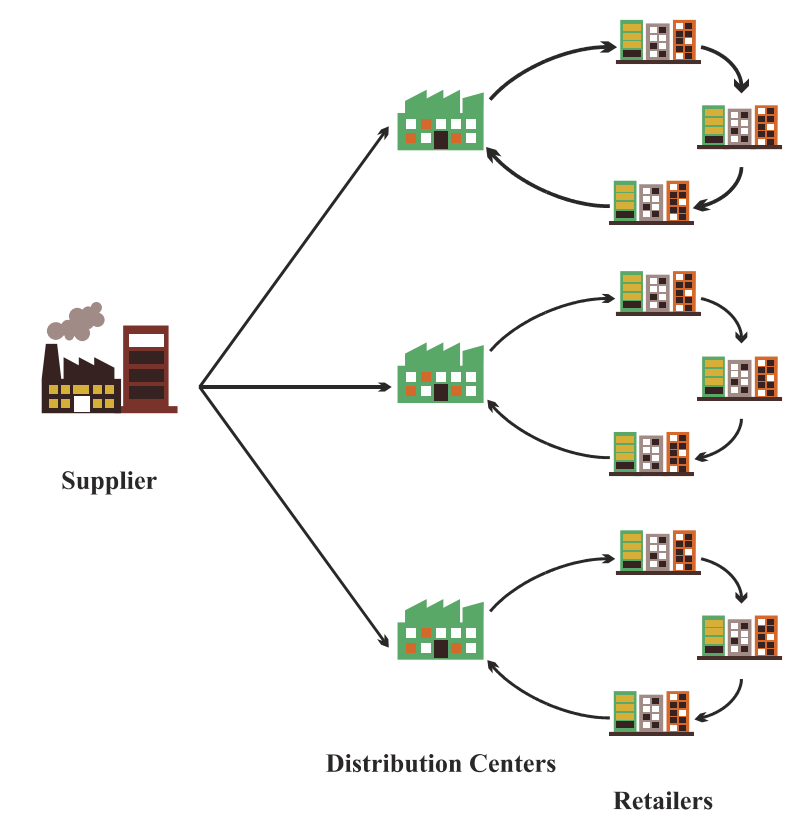

Fig. 1. Overall structure of considered supply chain network

Regarding the above LIRP problem, the following assumptions have been considered:

- Considered supply chain has three levels including a supplier and several distributors and retailers.

- Supplier and retailers have fixed and predetermined locations and the objective is to determine the optimal locations for the distributors.

- The inventory have been held only in the retailers' and distributors' warehouses.

- The Inventory policy will be determined only for retailers and distributors.

- The inventory policy intended for the retailers and distributors is $(S-1, S)$.

- Demands of the retailers are probabilistic and follow the Poisson distribution.

- Lead time for replenishing retailers by distributors is the function of shortage. So, this time is also probabilistic.

The most important purposes of the problem are as follows:

1. Determine the optimal location of distributors 
2. Allocating retailers to the localized distributors

3. Determine the optimal amount of inventory for the retailers and distributors

So that the total cost of designing supply chain including inventory holding and shortage costs, the cost of establishment and location, and the costs of ordering and purchase are minimized.

\subsection{Problem notations}

Notations used for the location-inventory problem is as follows. These symbols are similar to the location-inventory-routing problem which is described in the following, and the additional symbols related to the location-inventory-routing problem will be described in the same section.

Sets

$i \quad$ Set of retailers $i=1,2, \ldots, I$

$k \quad$ Set of distributers $k=1,2, \ldots, K$

\section{Parameters}

$f_{k} \quad$ The fixed cost for establishing distributor $k$

$h_{0 k} \quad$ Holding cost per unit for distributer $k$

$\pi_{0 k} \quad$ Shortage cost per unit for distributer $k$

$h_{i} \quad$ Holding cost per unit for retailer $i$

$\pi_{i} \quad$ Shortage cost per unit for retailer $i$

$\lambda_{i} \quad$ The annual demand rate for retailer $i$

$C_{0 k} \quad$ The purchase cost per unit related to distributor $k$ for buying from supplier

$A_{0 k} \quad$ Ordering cost for distributor $k$

$C_{i k} \quad$ The purchase cost per unit related to retailer $i$ for buying from distributor $k$

$A_{i k} \quad$ Ordering cost related to retailer $i$ for buying from distributor $k$

$\tau_{0 k} \quad$ The carrying time from supplier to distributor $k$

$\tau_{i k} \quad$ The carrying time from distributor $k$ to retailer $i$

Decision Variables

$I_{0 k}^{+} \quad$ Average inventory for distributor $k$

$I_{0 k}^{-} \quad$ Average shortage for distributor $k$

$I_{i}^{+} \quad$ Average inventory for retailer $i$ 
$I_{i}^{-} \quad$ Average shortage for retailer $i$

$\lambda_{0 k} \quad$ Annual demand rate received from retailers for distributor $k$

$W_{0 k} \quad$ Delay random variable for distributor $k$ warehouse, due to inventory shortage

$\bar{\tau}_{i} \quad$ The average lead time (procurement time) of retailer $i$ to receive the product

$z_{k} \quad$ A binary variable that equals to 1 if the distributor $k$ is established and 0 otherwise

$y_{i k}$

A binary variable that equals to 1 if the retailer $i$ is allocated to distributor $k$ and 0

otherwise

\subsection{Model description}

As mentioned earlier, in this supply chain, distributors' and retailers' inventory policy complies with the $(S-1, S)$ inventory policy. In this policy, upon receipt of a demand request and response to it, inventory levels reduced by one unit and by reducing each unit of inventory, an order will be sent to replace the dropped item. The demand which retailers receive is probabilistic and follows the Poisson distribution with the rate of $\lambda$. Since each retailer is only allocated to one distributor, the demand rate for a distributor is equal to sum of the demand rates of retailers that have been assigned to it which is calculated from the Eq. (1):

$$
\lambda_{0 k}=\sum_{i \in I} \lambda_{i} y_{i k} \quad \forall k \in K
$$

The time to transport the products from supplier to distributor $k$ is equal to $\tau_{0 k}$ and the time of transporting from distributor $k$ to retailer $i$ is equal to $\tau_{i k}$. In addition to the transport time from the distributor to the retailer, a lead time is considered to meet the needs of retailers. This lead time has a value when a distributor is faced with shortage and the retailer is forced to wait until the distributor was replenished. To calculate this time according to 'Little's law', we have (Wang et al., 2008):

$$
W_{0 k}=\frac{I_{0 k}^{-}}{\lambda_{0 k}} . \quad \forall k \in K
$$

When the shortage is zero, the lead time for elimination the shortage will also be zero and if the shortage is positive, retailers will wait to get the product until the shortage condition is resolved. So, the retailer's total lead time for replenishment will be equal to:

$$
\bar{\tau}_{i}=\sum_{k \in K}\left(\tau_{i k}+W_{0 k}\right) y_{i k}, \quad \forall i \in I
$$

which is equal to the sum of the lead times for retailers to get the product and the delay time due to shortage condition. To calculate the average inventory and the average shortage with the METRIC approach, we conduct as follows. The probability that the inventory level of distributor $k$ is equal to $j$ is:

$$
\operatorname{Pr}\left(I_{0 k}^{+}=j\right)=\operatorname{Pr}\left(S_{0 k}-D\left(\tau_{0 k}\right)=j\right)=\operatorname{Pr}\left(D\left(\tau_{0 k}\right)=S_{0 k}-j\right) \quad \forall k \in K
$$

According to a Poisson distribution, we have: 


$$
\operatorname{Pr}\left(D\left(\tau_{0 k}\right)=S_{0 k}-j\right)=\frac{e^{-\lambda_{0 k} \tau_{0 k}}\left(\lambda_{0 k} \tau_{0 k}\right)^{S_{0 k}-j}}{\left(S_{0 k}-j\right) !} \quad \forall k \in K
$$

So, the average inventory level in the distributor $k$ is calculated from the following expected value:

$$
I_{0 k}^{+}=\sum_{j=1}^{S_{0 k}} j\left[\frac{e^{-\left(\lambda_{0 k} \tau_{0 k}\right)}\left(\lambda_{0 k} \tau_{0 k}\right)^{S_{0 k}-j}}{\left(S_{0 k}-j\right) !}\right] \quad \forall k \in K
$$

Also, the average shortage for the distributor $k$ can also be determined as follows (Wang et al., 2008):

$$
I_{0 k}^{-}=\sum_{j=-\infty}^{-1}-j\left[\frac{e^{-\left(\lambda_{0 k} \tau_{0 k}\right)}\left(\lambda_{0 k} \tau_{0 k}\right)^{S_{0 k}-j}}{\left(S_{0 k}-j\right) !}\right] . \quad \forall k \in K
$$

Because of its infinite limit, it is difficult to solve this equation. Hence, we use the following method to get the average shortage:

$$
\begin{aligned}
& E\left(I_{0 k}\right)=I_{0 k}^{+}-I_{0 k}^{-} \\
& I_{0 k}^{-}=I_{0 k}^{+}-E\left(I_{0 k}\right)
\end{aligned}
$$

On the other hand, we have:

$$
E\left(I_{0 k}\right)=S_{0 k}-\lambda_{0 k} \tau_{0 k}
$$

So the average shortage is equal to:

$$
I_{0 k}^{-}=I_{0 k}^{+}-\left(S_{0 k}-\lambda_{0 k} \tau_{0 k}\right) \quad \forall k \in K
$$

In the same way, the average inventory and average shortage can be calculated for the retailers with this difference that lead time of retailers, which is calculated above, is equal to $\bar{\tau}_{i}$. The average inventory and average shortage values for the retailer $i$ are equal to the following equations:

$$
\begin{array}{ll}
I_{i}^{+}=\sum_{j=1}^{S_{i}} j\left[\frac{e^{-\left(\lambda_{i} \bar{\tau}_{i}\right)}\left(\lambda_{i} \bar{\tau}_{i}\right)^{S_{j}-j}}{\left(S_{j}-j\right) !}\right] & \forall i \in I \\
I_{i}^{-}=I_{i}^{+}-\left(S_{i}-\lambda_{i} \bar{\tau}_{i}\right) & \forall i \in I
\end{array}
$$

\subsection{Mathematical model}

According to the above description, mathematical model for the location-inventory problem will be as follows.

$$
\begin{aligned}
& \min z=\sum_{k \in K} f_{k} z_{k}+\sum_{i \in I}\left(h_{i} I_{i}^{+}+\pi_{i} I_{i}^{-}\right)+\sum_{k \in K}\left(h_{0 k} I_{0 k}^{+}+\pi_{0 k} I_{0 k}^{-}\right) \\
& +\sum_{k \in K} \lambda_{0 k}\left(C_{0 k}+A_{0 k}\right)+\sum_{k \in K} \sum_{i \in I} \lambda_{i}\left(C_{i k}+A_{i k}\right) y_{i k}
\end{aligned}
$$


subject to

$$
\begin{array}{lc}
\sum_{k \in K} y_{i k}=1 & \forall i \in I \\
y_{i k} \leq z_{k} & \forall k \in K ; \forall i \in I \\
\lambda_{0 k}=\sum_{i \in I} \lambda_{i} y_{i k} & \forall k \in K \\
I_{0 k}^{+}=\sum_{j=1}^{S_{0 k}} j\left[\frac{e^{-\left(\lambda_{0 k} \tau_{0 k}\right)}\left(\lambda_{0 k} \tau_{0 k}\right)^{S_{0 k}-j}}{\left(S_{0 k}-j\right) !}\right] & \forall k \in K \\
I_{0 k}^{-}=I_{0 k}^{+}-\left(S_{0 k}-\lambda_{0 k} \tau_{0 k}\right) & \\
W_{0 k}=\frac{I_{0 k}^{-}}{\lambda_{0 k}} & \forall k \in K \\
\bar{\tau}_{i}=\sum_{k \in K}\left(\tau_{i k}+W_{0 k}\right) y_{i k} & \forall k \in K \\
I_{i}^{+}=\sum_{j=1}^{S_{i}} j\left[\frac{e^{-\left(\lambda_{i} \bar{\tau}_{i}\right)}\left(\lambda_{i} \bar{\tau}_{i}\right)^{S_{j}-j}}{\left(S_{j}-j\right) !}\right] & \forall i \in I \\
I_{i}^{-}=I_{i}^{+}-\left(S_{i}-\lambda_{i} \bar{\tau}_{i}\right) & \forall i \in I \\
z_{k} \in\{0,1\} & \forall i \in I \\
y_{i k} \in\{0,1\} & \forall k \in K \\
S_{i} \in \text { int }^{+} & \forall k \in K ; \forall i \in I \\
S_{k} \in \text { int }^{+} & \forall i \in I \\
T h e=K
\end{array}
$$

The first part of the equation 14 or the objective function is devoted to the distributors' locating costs. The next part reflects the retailers' inventory holding and shortage costs, the distributors' inventory holding and shortage costs, the retailers' purchasing and ordering costs and the distributors' purchasing and ordering costs. Constraint 15 ensures that each retailer is only allocated to one distributor. Constraint 16 states that a retailer cannot be allocated to an inactive distributor. Constraints 17 to 23 are fully described before providing the mathematical model. Constraints 24 to 27 are the standard constraints of the mathematical model.

\section{Location-Inventory-Routing Problem with METRIC approach}

\subsection{Problem definition}

In the location-Inventory problem proposed in the previous section, it was said that several distributors are selected from the potential distributors set and retailers are allocated to these activated distributors such a way that the total cost is minimized. In the location-inventory-routing problem, in addition to previous decisions, the order of serving and the optimum route for transporting products from distributors to retailers are determined.

\subsection{Problem notations}

To develop the model presented in the previous section and proposing the location-Inventory-routing model in this section, we firstly describe the symbols. Most of the symbols of this model are identical to those of the previous model, and the following symbols should be added to previous symbols.

Sets

$v \quad$ Set of vehicles $v=1,2, \ldots, V$ 
Parameters

$T_{g h} \quad$ The transporting cost from node $g$ to node $h$

Q Vehicles capacity

Decision variables

$X_{g h v} \quad$ A binary variable that equals to 1 if the node $h$ is immediately served after $g$ by the vehicle $v$ and 0 otherwise;

$B_{\text {kghiv }} \quad$ A binary variable that equals to 1 if the vehicle $v$ from the distributor $k$ pass through the nodes of $g$ and $h$ to serve the retailer $i$ and 0 otherwise;

$N_{g v} \quad$ Auxiliary variable for sub-tour elimination in route of vehicle $v$ which is defined for retailer $g$

\subsection{Mathematical model}

$$
\begin{aligned}
& \min z=\sum_{k \in K} f_{k} z_{k}+\sum_{i \in I}\left(h_{i} I_{i}^{+}+\pi_{i} I_{i}^{-}\right)+\sum_{k \in K}\left(h_{0 k} I_{0 k}^{+}+\pi_{0 k} I_{0 k}^{-}\right) \\
& +\sum_{k \in K} \lambda_{0 k}\left(C_{0 k}+A_{0 k}\right)+\sum_{k \in K} \sum_{i \in I} \lambda_{i}\left(C_{i k}+A_{i k}\right) y_{i k}+\sum_{g \in M} \sum_{h \in M} \sum_{v \in V} T_{g h} X_{g h v}
\end{aligned}
$$

subject to

$$
\begin{array}{lc}
\sum_{k \in K} y_{i k}=1 & \forall i \in I \\
y_{i k} \leq z_{k} & \forall k \in K ; \forall i \in I \\
\lambda_{0 k}=\sum_{i \in I} \lambda_{i} y_{i k} & \forall k \in K \\
I_{0 k}^{+}=\sum_{j=1}^{S_{0 k}} j\left[\frac{e^{-\left(\lambda_{0 k} \tau_{0 k}\right)}\left(\lambda_{0 k} \tau_{0 k}\right)^{S_{0 k}-j}}{\left(S_{0 k}-j\right) !}\right] & \forall k \in K \\
I_{0 k}^{-}=I_{0 k}^{+}-\left(S_{0 k}-\lambda_{0 k} \tau_{0 k}\right) & \forall k \in K \\
W_{0 k}=\frac{I_{0 k}^{-}}{\lambda_{0 k}} & \forall k \in K \\
\tau_{i k}=\sum_{v \in V} \sum_{h \in I} \sum_{g \in M} T_{g h} B_{k g h i v} & \forall k \in K ; \forall i \in I \\
y_{i k} X_{g i v} \leq B_{k g i i v} & \forall k \in K ; \forall i \in I ; \forall g \in M ; \forall v \in V \\
X_{g h v} B_{k h l i v} \leq B_{k g h i v} & \forall k \in K ; \forall i \in I ; \forall h \in I ; \forall l \in I ; \forall g \in M ; \forall v \in V \\
B_{k g h i v} \leq X_{g h v} & \forall k \in K ; \forall i \in I ; \forall g \in M ; \forall h \in M ; \forall v \in V \\
\sum_{v \in V} B_{k g h i v} \leq z_{k} & \forall k \in K ; \forall i \in I ; \forall g \in M ; \forall h \in M \\
\bar{\tau}_{i}=\sum_{k \in K}\left(\tau_{i k}+W_{0 k}\right) y_{i k} \\
I_{i}^{+}=\sum_{j=1}^{S_{i}} j\left[\frac{e^{-\left(\lambda_{i} \bar{\tau}_{i}\right)}\left(\lambda_{i} \bar{\tau}_{i}\right)^{S_{j}-j}}{\left(S_{j}-j\right) !}\right] \\
\forall i \in I
\end{array}
$$




$$
\begin{array}{lc}
I_{i}^{-}=I_{i}^{+}-\left(S_{i}-\lambda_{i} \bar{\tau}_{i}\right) & \forall i \in I \\
\sum_{g \in M} \sum_{i \in I} \lambda_{i} X_{g i v} \leq Q & \forall v \in V \\
\sum_{g \in M} \sum_{v \in V} X_{g i v}=1 & \forall i \in I \\
\sum_{k \in K} \sum_{i \in I} X_{k i v} \leq 1 & \forall v \in V \\
\sum_{g \in M} X_{g h v}-\sum_{g \in M} X_{h g v}=0 & \forall h \in M ; \forall v \in V \\
\sum_{h \in M} X_{k h v}-\sum_{h \in M} X_{i h v}-y_{i k} \leq 1 & \forall k \in K ; \forall i \in I ; \forall v \in V \\
N_{i v}-N_{g v}+|I| X_{i g v} \leq|I|-1 & \forall i, g \in I ; \forall v \in V \\
z_{k} \in\{0,1\} & \forall k \in K \\
y_{i k} \in\{0,1\} & \forall k \in K ; \forall i \in I \\
X_{g h v} \in\{0,1\} & \forall g, h \in M ; \forall v \in V \\
B_{k g h i v} \in\{0,1\} & \forall k \in K ; \quad \forall i \in I ; \forall \in I ; \in M ; \forall v \in V \\
S_{i} \in \text { int }^{+} & \forall i \in I \\
S_{k} \in \text { int }^{+} & \forall k \in K
\end{array}
$$

The first part of the objective function is similar to the location-inventory problem objective function. The final part of the objective function represents the routing cost of vehicles and seeks a path that has the minimum cost for serving the needs of retailers. Constraints 29 to 34 and 40 to 42 are identical to the constraints of location-inventory problem presented in the previous section. The remaining constraints are as follows:

Constraint 35 calculates the transportation time from the retailer $i$ to the distributor $k$. Constraint 36 states that if the retailer $i$ is allocated to the distributor $k\left(y_{i k}=1\right)$ then there is a path from node $g$ to this retailer $\left(X_{g i v}=1\right)$, so, the path of node $g$ to $i$ is surely in the path of distributor $k$ to $i \quad\left(B_{k g i i v}=1\right)$. Constraint 37 is also conceptually similar to the previous constraint. This constraint states that if there is a path from node $g$ to node $h$, the path $h-i$ will be in the path from the distributor $k$ to the retailer $i$, then surely, the path $g-h$ will be also in the path of distributor $k$ to the retailer $i$. Constraint 38 states that when a path can be in the path of distributor $\mathrm{k}$ to the retailer $\mathrm{i}$ that it was active; otherwise, it is not possible to pass from the path and reach the retailer from the distributor. Constraint 39 states that we can have a path from a distributor if the distributor is active. Constraints 36 to 39 are supplements of the constraint 35 so that they cause the correct value for the variable $B$. Constraint 43 is the vehicles capacity constraint. Constraint 44 states that each retailer only assigned to a vehicle path. Constraint 45 ensures that several distributors cannot serve a path. Constraint 46 states that if a vehicle is entered to a node which is related to a retailer or a distributor, it will also exit from that node. Constraint 47 represents that a path cannot pass a retailer unless it is allocated to a distributor. Constraint 48 is the sub-tour elimination constraint and ensures that each path has a distributor as the start and end points of the route. Also, constraints 49 to 54 are the standard constraints of mathematical model.

\section{Solution approach}

The Genetic Algorithm (GA) was proposed in 1975 by John Holland. The basic idea of GA is based on evolutionary in nature. Consider a certain population of people in which the limitation of environmental resources has caused that they try for survival and reproduction based on their fitness. In the solving problem procure, consider a function that should be maximized. We can randomly generate a set of 
candidate solutions and consider the function value as the fitness level. The higher this value is, the higher the individual quality is. According to this fitness, the better individuals are selected as the parents for creating the next generation (using crossover and mutation operators). Fig. 2 shows a simple pseudocode for the genetic algorithm.

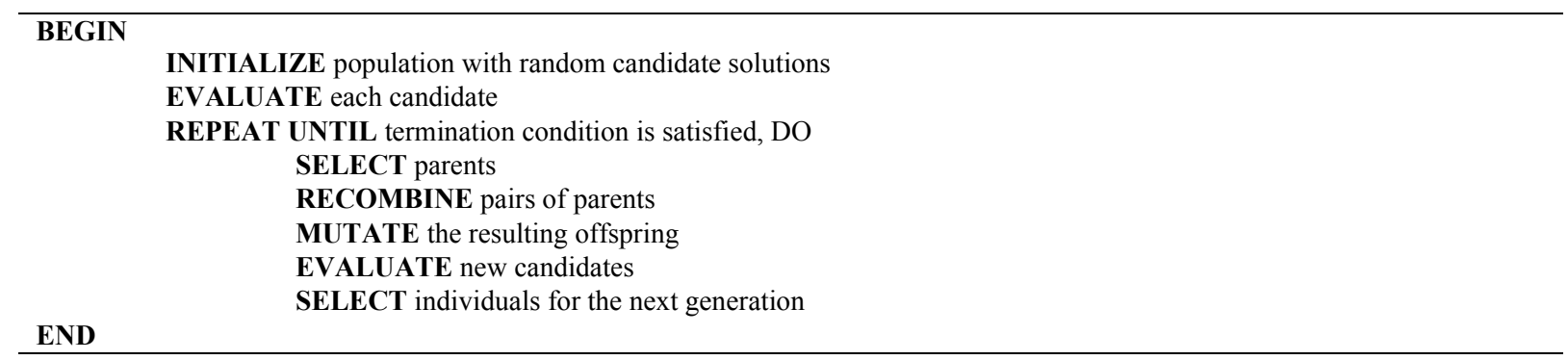

Fig. 2. Genetic Algorithm (GA) pseudocode

In 1935, Metropolis et al. (1953) presented a simple algorithm to simulate the process of heating and cooling of metals to reach the thermal equilibrium. Later, they used this algorithm to solve the optimization problems. In this algorithm, with starting from an initial state, the system is placed under the effects of a change. If the change leads to a reduction in the objective function (in a minimization problem) it will be accepted. Otherwise, if the change leads to an increase in the objective function, it will be accepted with the probability of $\exp \left(-\frac{\Delta E}{T}\right)$ where $-\Delta E$ represents the difference between two objective functions and $T$ indicates the temperature. In fact, the acceptance process, when the objective function will be worse, a number is randomly selected from the range of zero to one and then, if the number is less than or equal to $\exp \left(-\frac{\Delta E}{T}\right)$, the change will be accepted, and otherwise, it is rejected. This approach avoid getting stuck on a local optimum solution during the search process. Fig. 3 shows a pseudocode for the Simulated Annealing (SA) algorithm.

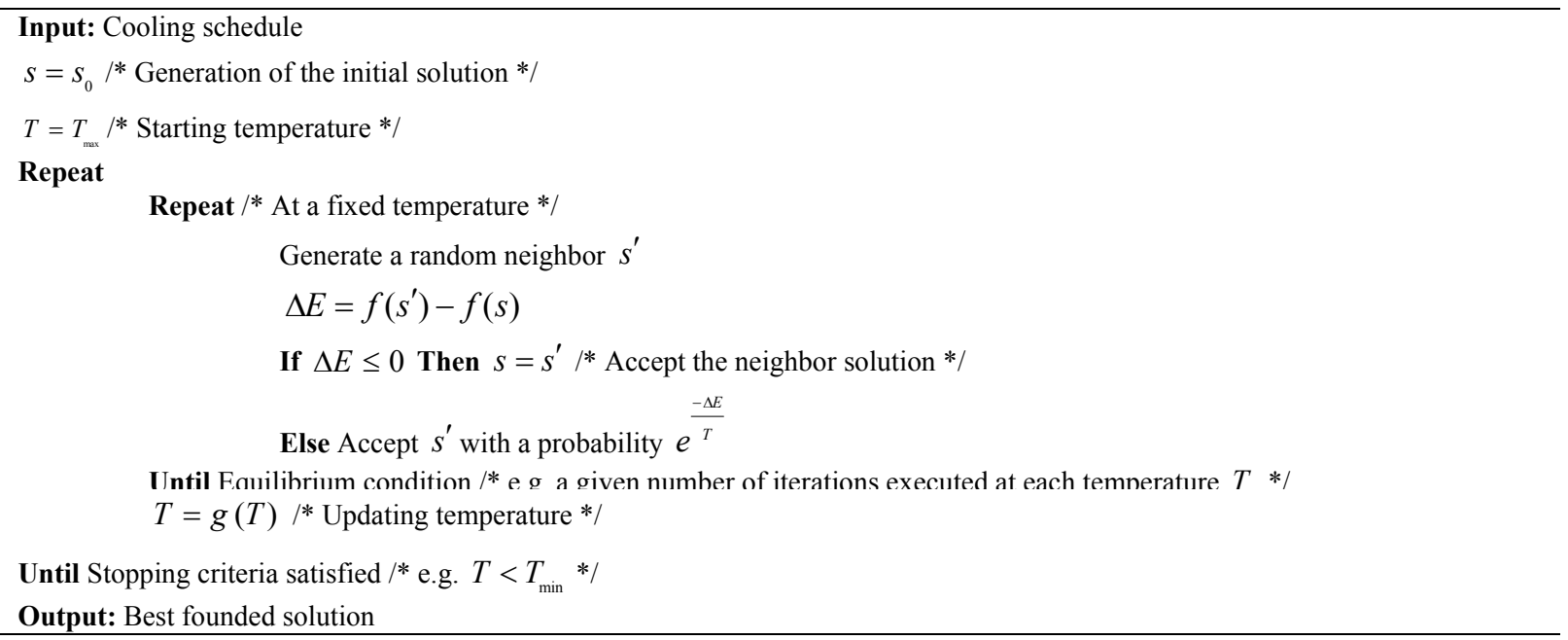

Fig. 3. Simulated Annealing (SA) algorithm pseudocode

Since the model presented in this paper belongs to the class of NP-hard problems, a hybrid metaheuristic algorithm is used to solve the model. In this algorithm, the inventory decisions have been optimized by the GA and routing, location and allocation decisions have been optimized by the SA algorithm. The reason of using these two algorithms for solving location-routing and inventory problems arises from the conclusions in previous studies. For example, in solving the location-routing problem presented by Vincent et al. (2010), SA has been used to solve the problem. We can also refer the studies Nekooghadirli et al. (2014), Javid and Azad (2010), and Seyedhosseini et al. (2014), which 
have used genetic algorithm to solve their problems. Here, one-dimensional matrix is used to show the solutions. For example, consider the following matrix. In this one-dimensional matrix, the negative values indicate the distributors and the positive values indicate the path. The number of zeros is calculated from the equation 55 (Vincent et al., 2010).

$$
n=\left\lceil\frac{\sum_{i} \lambda_{i}}{Q}\right\rceil,
$$

where $\lambda_{i}$ represents the demand of retail $i$ and $Q$ represents the vehicle capacity and $\lceil *\rceil$ represents the smallest integer greater than or equal to *. Fig. 4 shows a feasible solution for the problem.

\begin{tabular}{|l|l|l|l|l|l|l|l|l|l|l|l|l|l|l|l|l|l|l|l|l|l|l|l|l|l|l|l|l|l|}
\hline-24 & 0 & 0 & -25 & 10 & 9 & 17 & 2 & -23 & 14 & 15 & 16 & 19 & 0 & 8 & 11 & 6 & -22 & 0 & 0 & 4 & 1 & 12 & 18 & 20 & 13 & 5 & 7 & 3 & -21 \\
\hline
\end{tabular}

Fig. 4. A feasible solution matrix

Above matrix can be shown as Fig. 5:

$(10)$

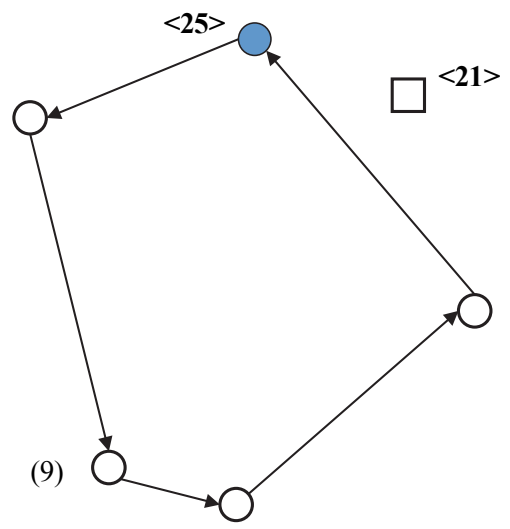

(2)

(16)

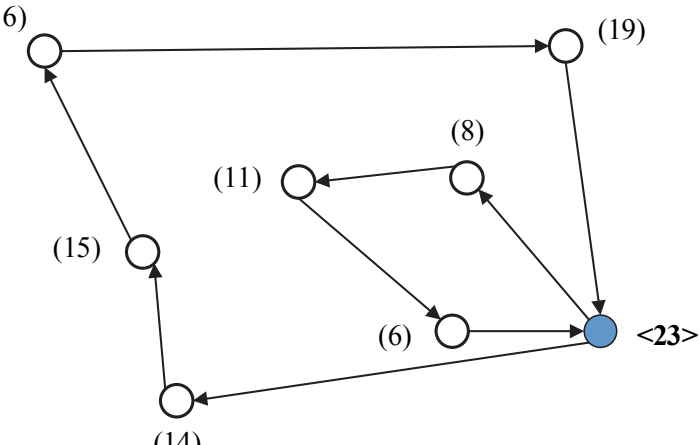

(18)

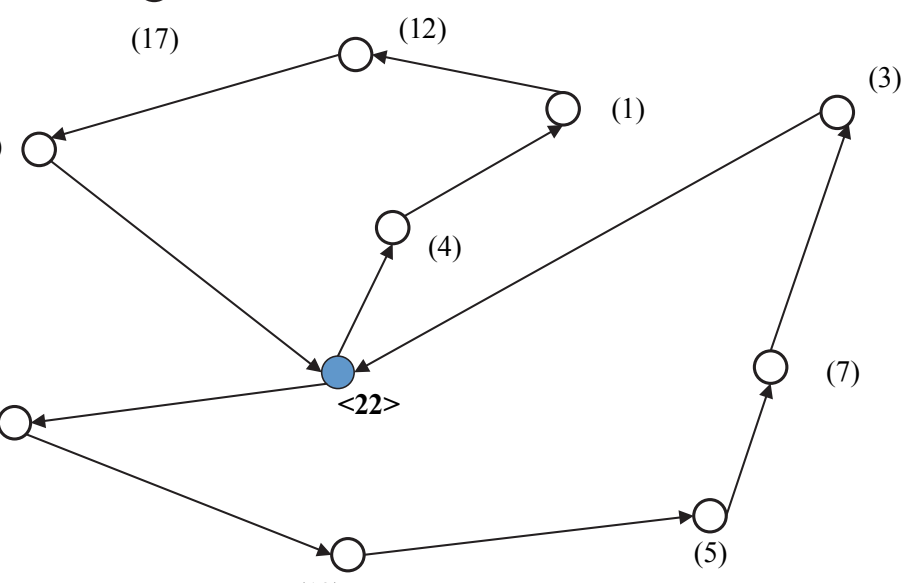

(3)

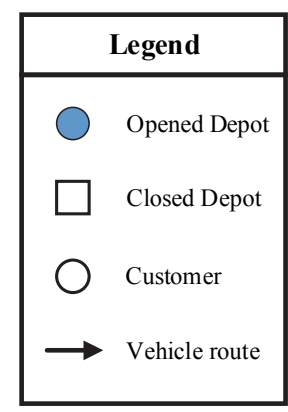

(13)

Fig. 5. A schematic representation for considered matrix

This answer matrix is improved at each iteration by using SA algorithm and it is transferred to GA. Based on this answer, GA generates and improves the inventory problem solution and then the solution obtained at two stages has been combined together and the total solution will be obtained. In other 
words, according to the solution obtained by the SA algorithm, GA generates and improves a solution for the inventory problem. In this way, the GA, according to the received answer, extract the number of active distributors and form the initial solution. For example, if the number of active distributors is equal to 2 and the number of active retailers is equal to 6 , the solution will be considered as an 8-bit vector whose values indicate the inventory level $S$ for the active distributors and retailers. In this case, in the GA, the chromosome can be shown as follows.

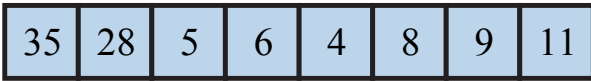

Fig. 6. An example of inventory decisions in the form of chromosome

To generate neighborhood in this algorithm, two operators of crossover and mutation have been used. To generate neighborhood in crossover operator, there are two modes in which, two chromosomes are selected as parents and then, the offsprings are generated by using one of the following methods:

1. Given the following two chromosomes in Fig. 7, in the first method, a random number is generated less than the size of chromosomes. Suppose that in this example our random number is 5. It means that the chromosomes replace the fifth elements onwards with each other.

\begin{tabular}{|l|l|l|l|l|l|l|l|l|}
\hline Parent chromosome 1 & 35 & 28 & 5 & 6 & 4 & 8 & 9 & 11 \\
\hline Parent chromosome 2 & 42 & 32 & 9 & 10 & 8 & 12 & 6 & 7 \\
\hline
\end{tabular}
\begin{tabular}{|l|l|l|l|l|l|l|l|l|}
\hline Child chromosome 1 & 35 & 28 & 5 & 6 & 4 & 12 & 6 & 7 \\
\hline Child chromosome 2 & 42 & 32 & 9 & 10 & 8 & 8 & 9 & 11 \\
\hline
\end{tabular}

Fig. 7. Neighborhood generation procedure in the first method

2. In the second case, the neighborhood generation is similar to the first method with the difference that the fraction and displacement occurs in two points.

\begin{tabular}{|l|l|l|l|l|l|l|l|c|}
\hline Parent chromosome 1 & 35 & 28 & 5 & 6 & 4 & 8 & 9 & 11 \\
\hline Parent chromosome 2 & 42 & 32 & 9 & 10 & 8 & 12 & 6 & 7 \\
\hline
\end{tabular}
\begin{tabular}{|l|c|c|c|c|c|c|c|c|}
\hline Child chromosome 1 & 35 & 28 & 5 & 10 & 8 & 12 & 9 & 11 \\
\hline Child chromosome 2 & 42 & 32 & 9 & 6 & 4 & 8 & 6 & 7 \\
\hline
\end{tabular}

Fig. 8. Neighborhood generation procedure in the second method 
Also, in the mutation operator a random number is generated and replaced with one of the parent's chromosomes elements. For example, if the random number is equal to 15 , mutation will occur as follows:

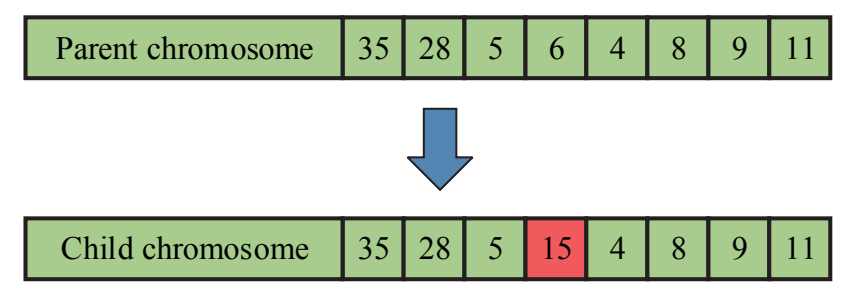

Fig. 9. Mutation operator

The hybrid algorithm proposed to solve the problem is shown schematically in Fig. 10.

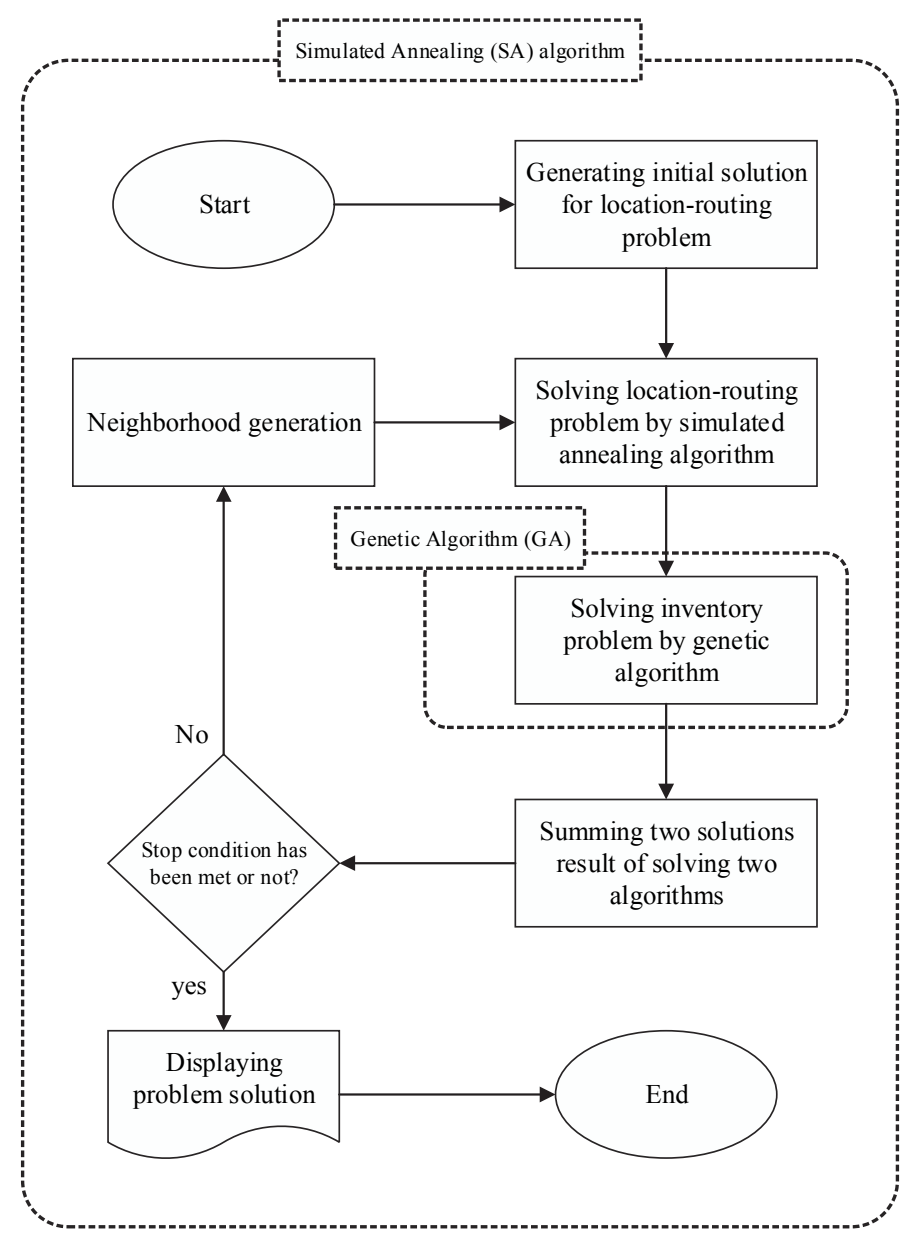

Fig. 10. Schematic representation of the proposed hybrid algorithm

This hybrid algorithm starts with the simulated annealing algorithm and continues with generating initial solutions for location-routing problem. The solutions will be improved by using this algorithm. The solution of the SA algorithm will be transferred to genetic algorithm. The GA generates and improves the inventory problem solution according to the solution received from the previous stage. The solutions obtained from the two stages sum together and if the stop condition is meet, the algorithm will end. Otherwise, the algorithm continues and the answer also improves. 


\section{Computational results}

In this section, in order to validate the presented model as well as the proposed hybrid metaheuristic algorithm, the computational results have been expressed. As a result, the studied model was coded using the proposed metaheuristic solution algorithm provided in the software Matlab 2015a and was run on a system with Windows 7-64bit OS, core i7 $2.0 \mathrm{GHz}$ processor, and $8 \mathrm{~GB}$ of RAM. In order to produce various test problems to solve the problem by the proposed algorithm, the randomly generated data which are followed the uniform distribution was used for the values of model parameters. Table 1 shows the values and statistical distribution of these parameters.

Table 1

Statistical distribution used for problem parameters

\begin{tabular}{ccc}
\hline \multirow{2}{*}{ Parameter } & \multicolumn{2}{c}{ Uniform distribution parameters } \\
\cline { 2 - 3 }$f_{k}$ & 3000 & $\mathrm{~B}$ \\
\hline$h_{i}$ & 3 & 5500 \\
$\pi_{i}$ & 7 & 6 \\
$h_{0 k}$ & 3 & 10 \\
$\pi_{0 k}$ & 7 & 6 \\
$C_{0 k}$ & 20 & 10 \\
$A_{0 k}$ & 20 & 40 \\
$\lambda_{i}$ & 1 & 40 \\
$C_{i k}$ & 25 & 40 \\
$A_{i k}$ & 20 & 45 \\
$T_{g h}$ & 0 & 40 \\
\hline
\end{tabular}

In order to increase the efficiency of the proposed solution algorithms, Taguchi method was used to tune their parameters. The tuned parameters for the two algorithms of SA and GA are shown in Tables 2 and 3 , respectively.

Table 2

Tuned parameters of simulated annealing algorithm

\begin{tabular}{ccccc}
\hline $\mathrm{T}_{\text {initial }}$ & $\mathrm{T}_{\min }$ & $\mathrm{R}$ & ISA-main & ISA-inner \\
\hline 700 & 0.01 & 0.9 & 20 & 5 \\
\hline
\end{tabular}

Table 3

Tuned parameters of genetic algorithm

\begin{tabular}{cccc}
\hline Pop Size & P $_{\text {crossover }}$ & P $_{\text {mutation }}$ & I $_{\text {GA }}$ \\
\hline 250 & 50 & 0.9 & 0.2 \\
\hline
\end{tabular}

The presented model is solved 3 times in 3 sizes of small, medium and large with considering the values of the Table 1 for the parameters and the results of solved problems in two exact and hybrid metaheuristic methods are presented in Table 4. Also, the error percentage in metaheuristic method compared to the exact method can be seen in the last column of Table 4 as follows, 
Table 4

The results from solving proposed LIRP model

\begin{tabular}{|c|c|c|c|c|c|c|c|}
\hline \multirow{2}{*}{$\begin{array}{l}\text { Problem } \\
\text { Size }\end{array}$} & \multirow{2}{*}{$\begin{array}{l}\text { Number of } \\
\text { distributers }\end{array}$} & \multirow{2}{*}{$\begin{array}{l}\text { Number of } \\
\text { retailers }\end{array}$} & \multicolumn{2}{|c|}{ Exact } & \multicolumn{2}{|c|}{ Metaheuristic } & \multirow{2}{*}{$\begin{array}{c}\text { Error } \\
\text { percentage }\end{array}$} \\
\hline & & & Cost & Time & Cost & Time & \\
\hline \multirow{5}{*}{ Small } & 1 & 3 & 12482.80 & 3 & 12483.30 & 40.65 & $\% 0.004$ \\
\hline & 2 & 4 & 12146.63 & 184 & 12246.44 & 51.72 & $\% 0.83$ \\
\hline & 3 & 6 & 15004.29 & 1335 & 15608.96 & 115.23 & $\% 4.03$ \\
\hline & 4 & 10 & 26988.35 & 5874 & 28267.59 & 289.32 & $\% 4.74$ \\
\hline & 6 & 15 & 44331.11 & 41715 & 45776.30 & 856.32 & $\% 3.26$ \\
\hline \multirow{3}{*}{ Medium } & 10 & 30 & $* *$ & $* *$ & 112856.36 & 4216.22 & - \\
\hline & 14 & 45 & $* *$ & $* *$ & 159633.36 & 4563.20 & - \\
\hline & 20 & 60 & $* *$ & $* *$ & 242912.59 & 4536.25 & - \\
\hline \multirow{4}{*}{ Large } & 25 & 70 & $* *$ & $* *$ & 268362.36 & 4625.25 & - \\
\hline & 30 & 90 & $* *$ & $* *$ & 298665.36 & 6593.26 & - \\
\hline & 35 & 120 & $* *$ & $* *$ & 384569.36 & 4838.36 & - \\
\hline & 40 & 150 & $* *$ & $* *$ & 459553.85 & 5986.22 & - \\
\hline
\end{tabular}

** The large size problems is not solvable by using Lingo software

As can be seen in Fig. 11, the use of metaheuristic solution algorithm decreases the computation time in solving large problems. By enlarging the size of problem, the computation time of exact method exponentially increases.

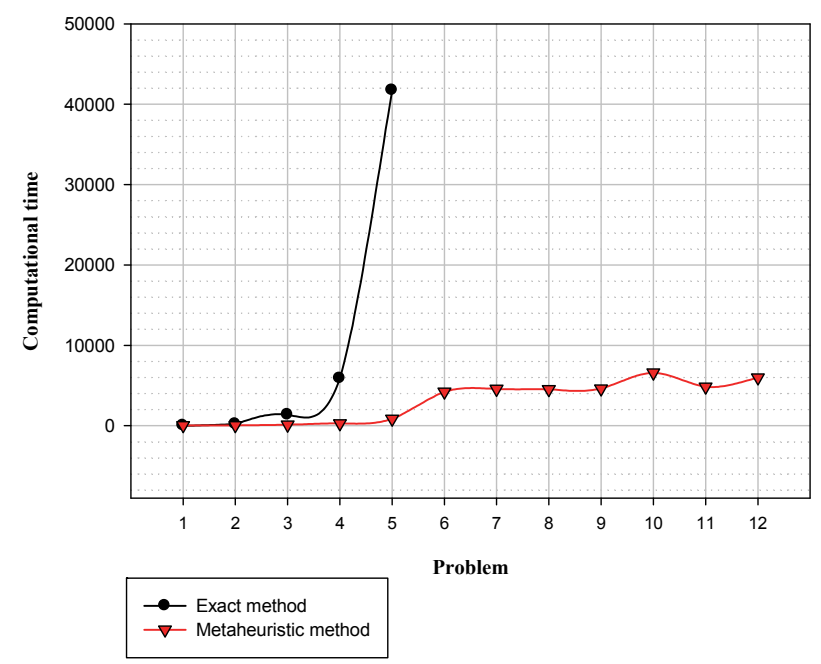

Fig. 11. Comparing exact and metaheuristic methods based on computational time

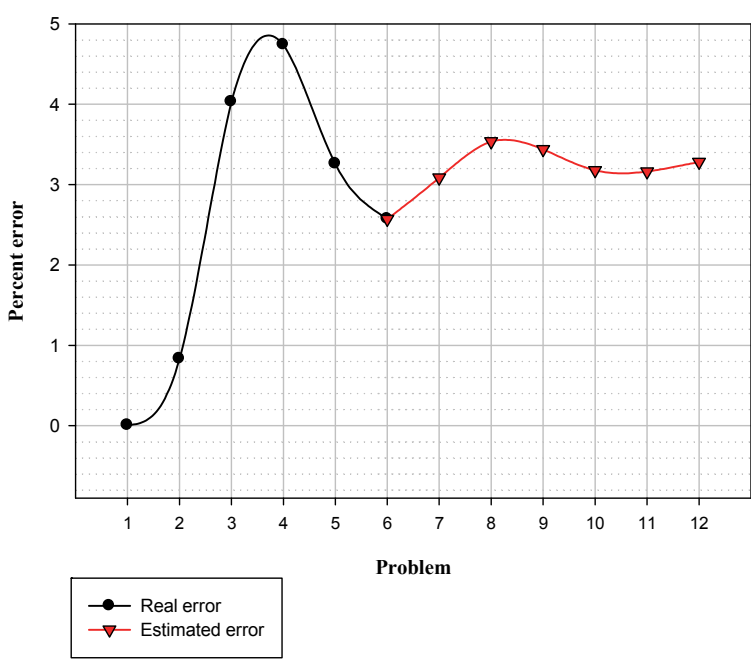

Fig. 12. The error of metaheuristic method compared to the exact method

The error percentage values obtained from metaheuristic algorithm compared to the exact method is displayed in Fig. 12. Red line shows the predicted values for the error determined by the moving average method with considering $n=5$. As can be seen, the error percentage is significantly inconsiderable and according to more appropriate computational time for medium and large problems, the use of proposed solution method is more efficient.

\section{Sensitivity analysis}

For the sensitivity analysis, the fifth problem of Table 4 which is consisted of 6 distributors and 15 retailers has been studied. To know whether the problem has proper behavior in the face of changing parameters, it is necessary to observe the effects of parameters on three values in the problem. These 
three values include: objective function value, optimal amount of base stock $(S)$ for distributers, and optimal amount of base stock $(S)$ for retailers.

- Sensitivity analysis based on the distributors' ordering cost: In this analysis, the relationship between the objective function and the distributors' ordering cost has been studied. As can be seen in Fig. 13, with increasing in the distributors' ordering cost, the objective function value increases linearly. In other words, there is a direct relation between these two values.

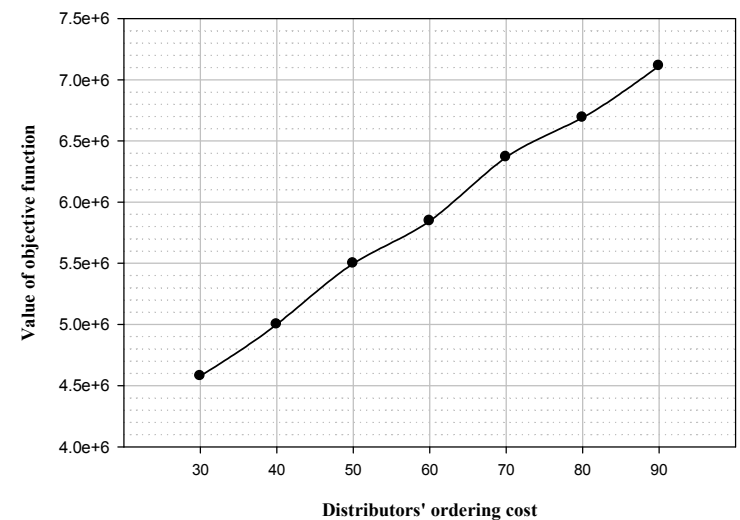

Fig. 13. Sensitivity analysis of objective function based on distributors' ordering cost

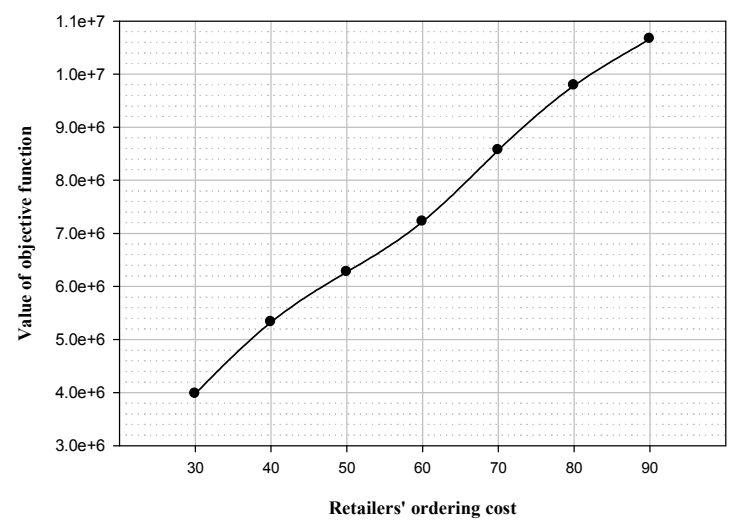

Fig. 14. Sensitivity analysis of objective function based on retailers' ordering cost

Also, the relationship between objective function and the retailers' ordering cost has been investigated. In this analysis, it is also observed that the objective function value increases with an increase in the retailers' ordering cost. This analysis confirms logical relations. Because by observing the objective function, we can also understand this issue. In the objective function, it was observed that the value of $A$ has a direct impact on the objective function and the value of objective function increases by increasing in its value.

- Sensitivity analysis based on transporting time from the supplier to distributors (in days):

Another analysis that should be done is the effect of transporting time from supplier to distributor on other values. The effect of this parameter on the three values of the objective function, the distributors' optimal base stock $(S)$ and retailers' optimal base stock $(S)$ has been studied.

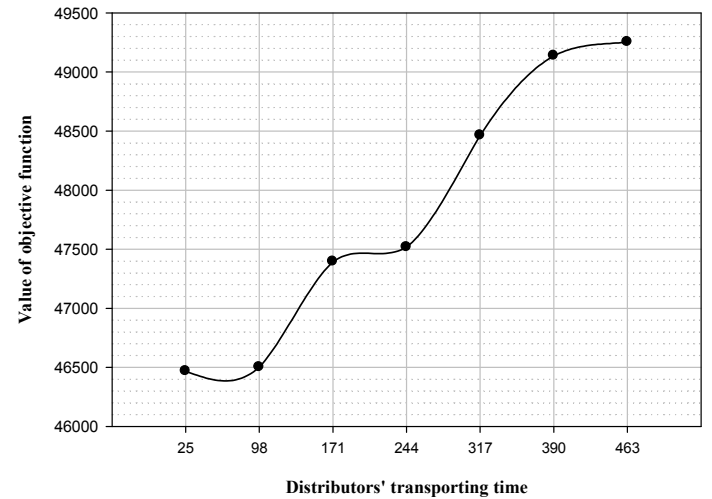

Fig. 15. Sensitivity analysis of objective function based on distributors' transporting time

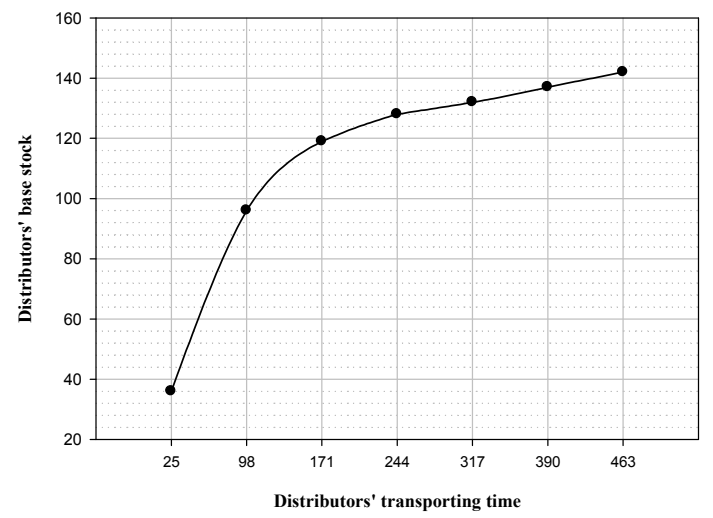

Fig. 16. Sensitivity analysis of distributors' base stock based on distributors' transporting time 
As can be seen in Fig. 15, with increasing in transporting time from supplier to distributor, the value of objective function also increases. This increase can be the result of the increase in inventory level that should be hold. Because by increasing in the transport time, the amount of inventory increases to prevent the creation of a massive shortage .Also, Fig. 16 and Fig. 17 confirm this issue.

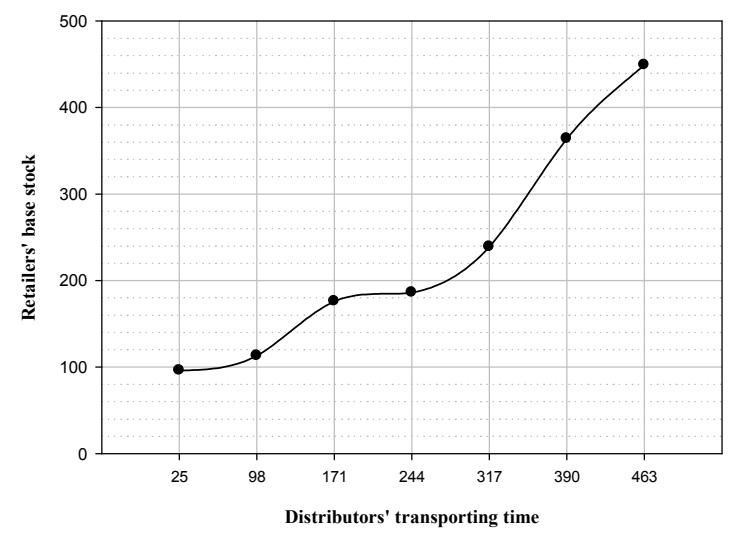

Fig. 17. Sensitivity analysis of retailers' base stock based on distributors' transporting time

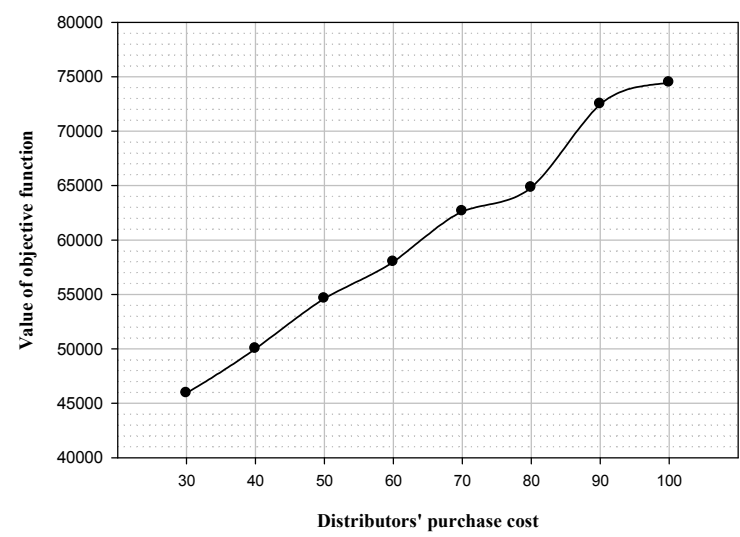

Fig. 18. Sensitivity analysis of objective function based on distributors' purchase cost

- Sensitivity analysis of objective function based on distributors' purchasing cost from the supplier:

Fig. 18 shows the effect of the distributor's purchasing cost from the supplier on the objective function. It is reasonable that with increasing trend in this cost, the value of the objective function also increases.

- Sensitivity analysis of retailers' and distributors' optimal base stock:

By increasing in the shortage cost, to avoid facing shortage, the value of base stock $(S)$ will increase. Also, if the inventory hooding cost increases, naturally the amount of holding inventory should be reduced so that the inventory holding cost is being adjusted. These issues can be seen in Fig. 19 and Fig. 20, respectively.
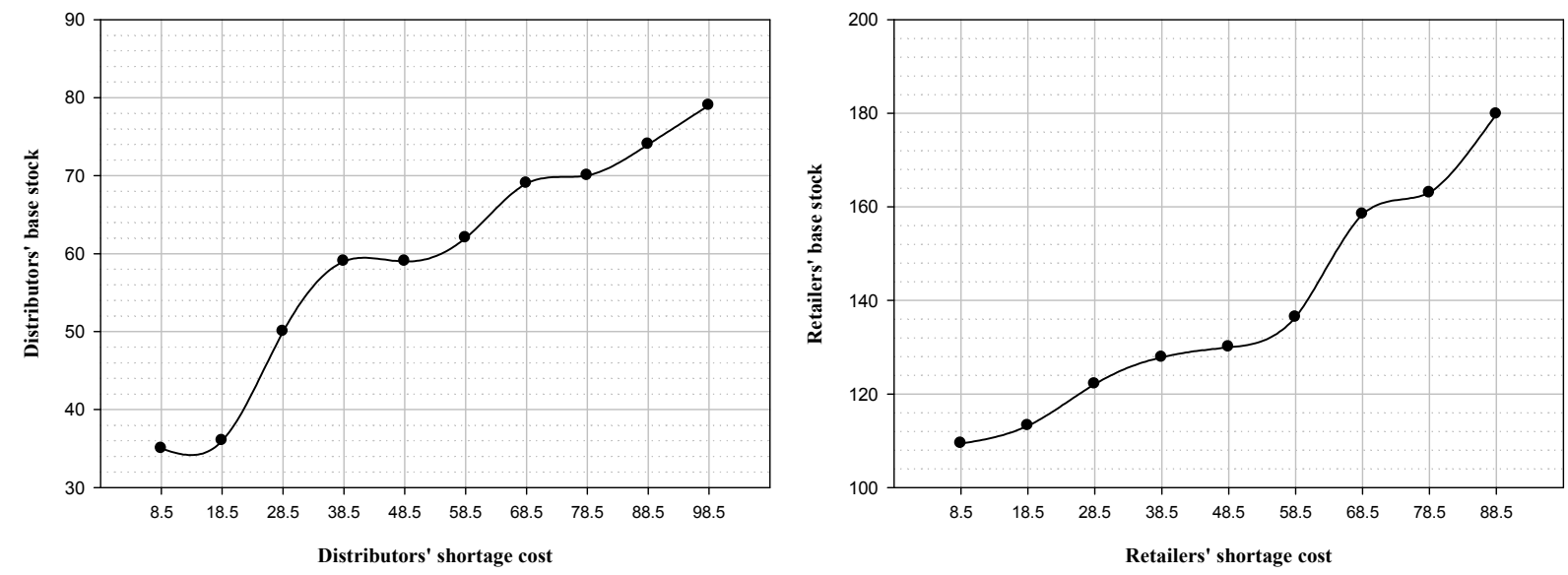

Fig. 19. Sensitivity analysis based on shortage costs 

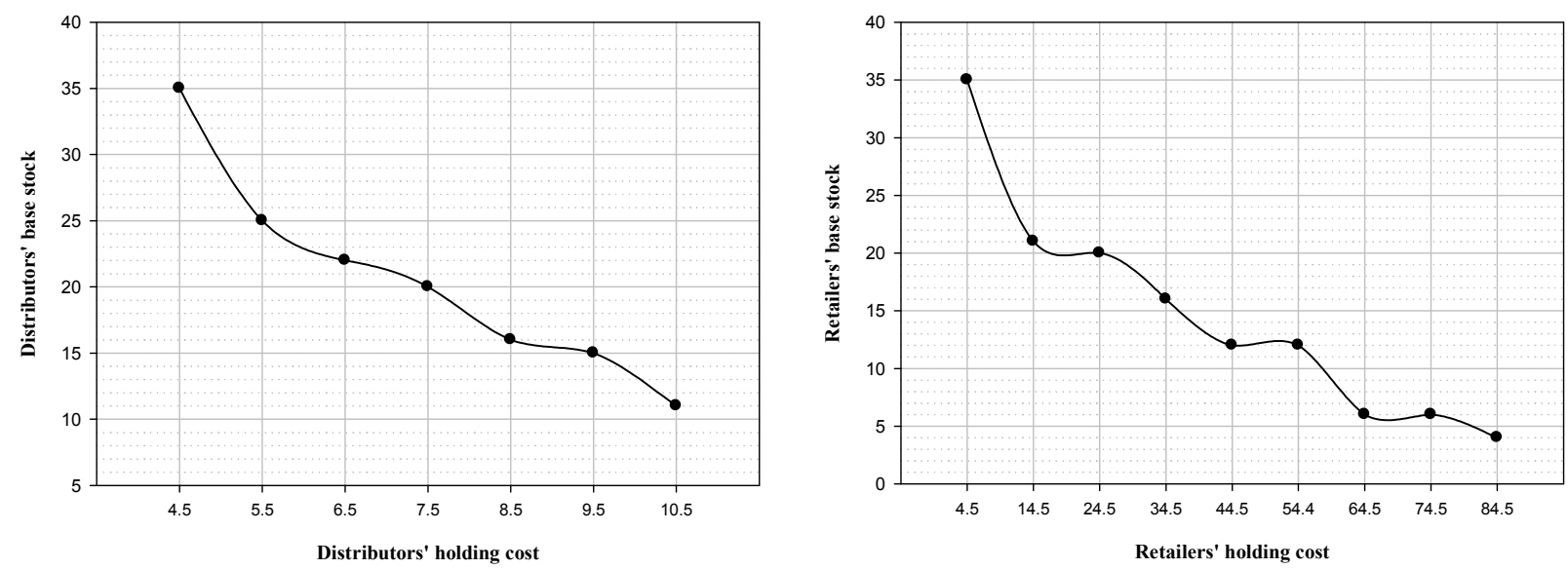

Fig. 20. Sensitivity analysis based on holding costs

- Sensitivity analysis based on demand rate: Another important parameter that needs to be analyzed is the demand rate. The effects of this parameter on three values of objective function, retailer's base stock, and distributors' base stock is also studied. As can be seen, increasing in this parameter leads to increasing in amount of this three values. This issue is not out of mind, because by increasing in demand, the inventory level should be increased to reduce possibility of facing the shortage.

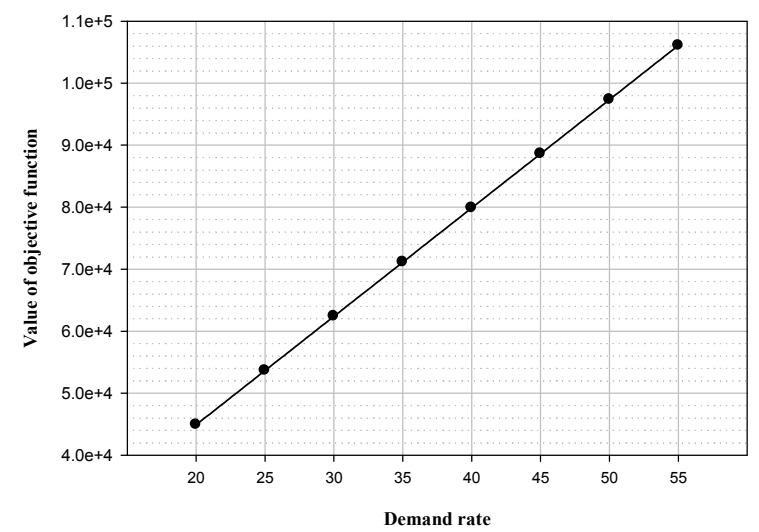

Fig. 21. Sensitivity analysis of objective function based on demand rate

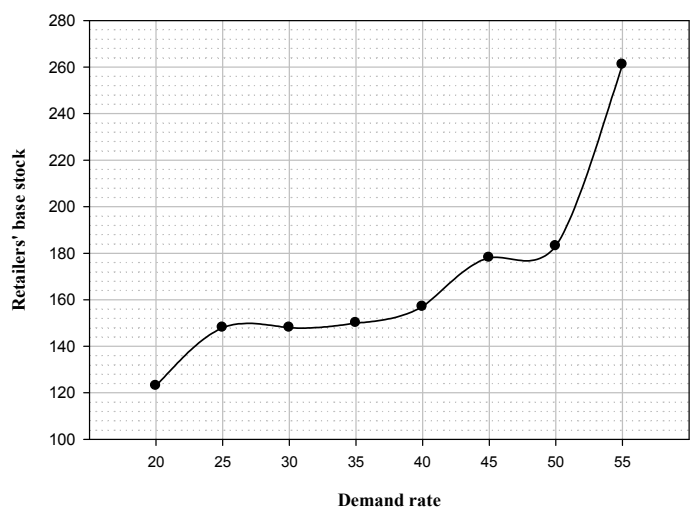

Fig. 22. Sensitivity analysis of retailers' base stock based on demand rate

According to Fig. 21 and observing the objective function changes trend towards increasing demand, we can found that the objective function has also increased. This increase is absolutely logical, because with increasing demand rate, holding, shortage and ordering costs also increases. Fig. 22 represents that by increasing in rate of demand, the optimal inventory level of $S$ in retailers will also increase.

This issue is occurred due to increased demand to avoid shortage. Increasing retailers' demand also causes the increase in the distributors' demand. So, it is logical that the amount of $S$ related to distributors is increased by increasing the retailers' demand. Fig. 23 also confirms this theme.

- Sensitivity analysis of objective function based on distributors' and retailers' holding costs, simultaneously:

For better understanding, the impact of distributors' and retailers' holding costs are analyzed simultaneously. Fig. 24 shows the effects of these two parameters. In this analysis, distributors' holding cost increases from low to high value and the retailers' holding costs has decreased from high to low 
value. The amount of increasing and decreasing have occurred simultaneously and have equalled to a same value. However, the objective function value is increased by these changes, the analysis shows that the impact of distributors' holding cost on the objective function is more than that of retailers' holding cost. This issue shows that the objective function is more sensitive to distributors' holding cost parameter.

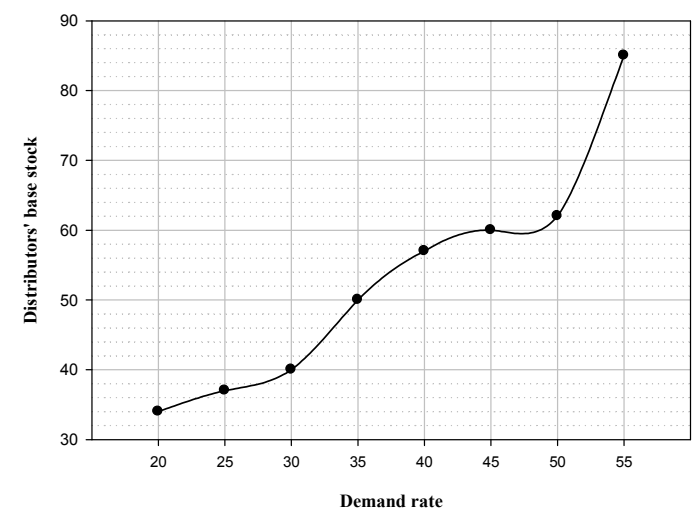

Fig. 23. Sensitivity analysis of distributors' base stock based on demand rate

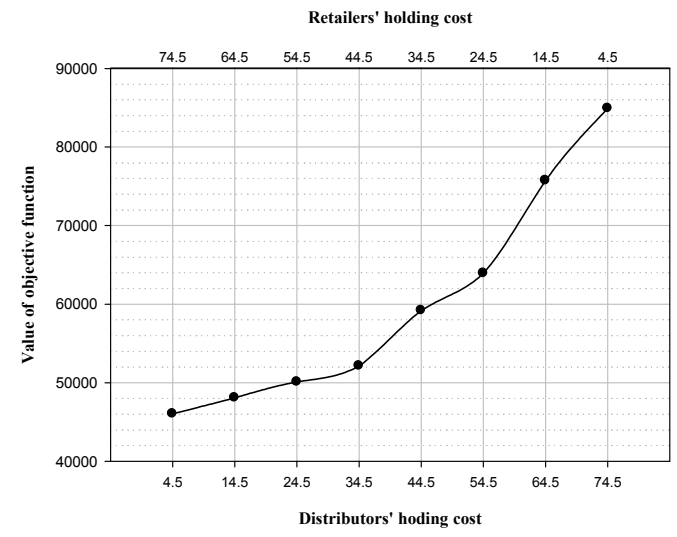

Fig. 24. Sensitivity analysis of objective function based on distributors' and retailers' holding cost

So, according to this analysis, what the managers and decision makers need to consider, is a greater focus on distributors' holding cost than the retailers' holding cost; because the reduction in distributors' holding cost has greater positive impact than the reduction in retailers' holding cost. The same analysis can be applied to the shortage cost as follows.

- Sensitivity analysis of objective function based on distributors' and retailers' shortage costs, simultaneously:

In this analysis, the effects of distributors' and retailers' shortage cost parameters on the objective function are analyzed simultaneously. As can be seen in Fig. 25, the shortage cost increases for the distributor and simultaneously reduces for the retailer. We can also conclude that the distributors' shortage cost has a greater effect on the objective function

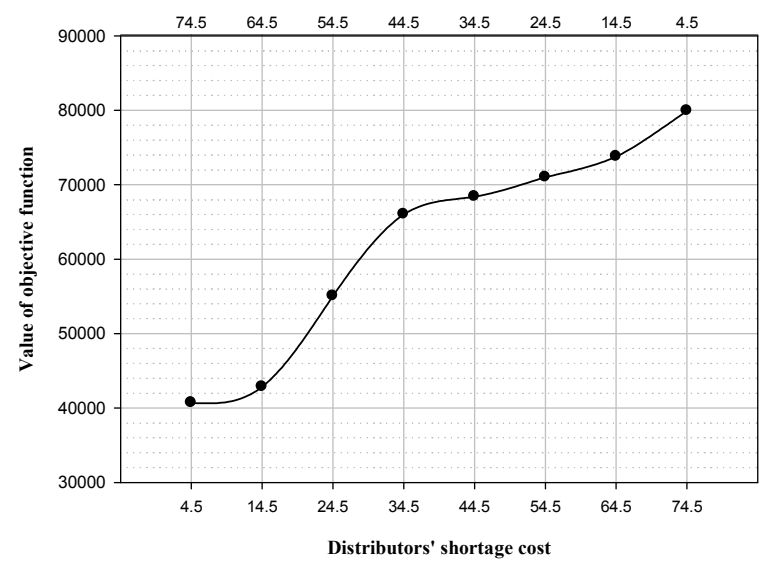

Fig. 25. Sensitivity analysis of objective function based on distributors' and retailers' shortage costs

\section{Conclusion and future research}

As it is expressed earlier, a supply chain involves different levels of decision-making in which macro level includes strategic and long-term decisions. The next level includes medium-term or tactical 
decisions and the operational and short-term decisions are in the next level. Organizations are required to continuously improve their performance to survive in this competitive world and one of the most important improvements can be considered in the decisions related to the supply chain. Location and allocation are the two kinds of strategic decisions; inventory management and control is one of the tactical decisions and the decisions related to transportation problem can be mentioned as the operational decisions. Therefore, in this study, an integrated supply chain model with considering uncertain conditions is proposed, which optimizes all location, inventory, transportation and routing decisions. In this study, we firstly presented the location-inventory model with considering uncertainty condition and using METRIC approach and then, the model was developed by adding the routing decisions. The policy which is considered for inventory, was the $(S-1, S)$ policy. Since the presented model belongs to the class of NP-hard problems, a hybrid GA-SA algorithm is proposed to solve the problem. Finally, 12 test problems in small, medium and large sizes have been solved and the effect of the parameters on the distributors' and retailers' base stocks $(S)$ and the objective function were analyzed.

It is recommended for the future research that the problem are also taken into consideration with the aim of minimizing transport time and minimizing the risk. Also, the use of multi-objective and twolevel models is also among the issues that have received less attention in location-inventory-routing problems. Utilizing the green supply chain topic is another development that could increase the attractiveness of the issue; since green supply chain management is one of the most important needs of today's world such a way that many governments have encouraged organizations to fulfill these green goals. Location- inventory-routing model has the potential to be widely used in green supply chain optimization.

\section{References}

Ambrosino, D., \& Scutella, M. G. (2005). Distribution network design: New problems and related models. European Journal of Operational Research, 165(3), 610-624.

Andersson, J., \& Melehiors, P. (2001). A two-echelon inventory model with lost sales. International Journal of Production Economics, 69(3), 307-315.

Bertazzi, L., Savelsbergh, M., \& Speranza, M. G. (2008). Inventory routing. In The vehicle routing problem: latest advances and new challenges (pp. 49-72). Springer US.

Campbell, A., Clarke, L., Kleywegt, A., \& Savelsbergh, M. (1998). The inventory routing problem. In Fleet management and logistics (pp. 95-113). Springer US.

Cordeau, J. F., Laporte, G., Savelsbergh, M. W., \& Vigo, D. (2007). Vehicle routing. Handbooks in operations research and management science, 14, 367-428.

Farahani, R. Z., Rashidi Bajgan, H., Fahimnia, B., \& Kaviani, M. (2015). Location-inventory problem in supply chains: a modelling review. International Journal of Production Research, 53(12), 37693788.

Graves, S. C. (1985). A multi-echelon inventory model for a repairable item with one-for-one replenishment. Management Science, 31(10), 1247-1256.

Hiassat, A., \& Diabat, A. (2011). A location-inventory-routing problem with perishable products. In Proceedings of the 41 st International Conference on Computers and Industrial Engineering.

Javid, A. A., \& Azad, N. (2010). Incorporating location, routing and inventory decisions in supply chain network design. Transportation Research Part E: Logistics and Transportation Review, 46(5), 582-597.

Jiang, S., \& Ma, Z. (2009). A hybrid genetic algorithm for the stochastic dynamic location-routinginventory problem in closed-loop logistics system for reusing end-of-use products. In International Conference on Transportation Engineering 2009 (pp. 4055-4060).

Liu, S. C., \& Lee, S. B. (2003). A two-phase heuristic method for the multi-depot location routing problem taking inventory control decisions into consideration. The International Journal of Advanced Manufacturing Technology, 22(11-12), 941-950. 
Liu, S. C., \& Lin, C. C. (2005). A heuristic method for the combined location routing and inventory problem. The International Journal of Advanced Manufacturing Technology, 26(4), 372-381.

Melo, M. T., Nickel, S., \& Saldanha-Da-Gama, F. (2009). Facility location and supply chain management-A review. European Journal of Operational Research, 196(2), 401-412.

Metropolis, N., Rosenbluth, A. W., Rosenbluth, M. N., Teller, A. H., \& Teller, E. (1953). Equation of state calculations by fast computing machines. The Journal of Chemical Physics, 21(6), 1087-1092.

Min, H., Jayaraman, V., \& Srivastava, R. (1998). Combined location-routing problems: A synthesis and future research directions. European Journal of Operational Research, 108(1), 1-15.

Muckstadt, J. A. (1973). A model for a multi-item, multi-echelon, multi-indenture inventory system. Management science, 20(4-part-i), 472-481.

Nagy, G., \& Salhi, S. (2007). Location-routing: Issues, models and methods. European Journal of Operational Research, 177(2), 649-672.

Nekooghadirli, N., Tavakkoli-Moghaddam, R., Ghezavati, V. R., \& Javanmard, S. (2014). Solving a new bi-objective location-routing-inventory problem in a distribution network by metaheuristics. Computers \& Industrial Engineering, 76, 204-221.

Owen, S. H., \& Daskin, M. S. (1998). Strategic facility location: A review. European Journal of Operational Research, 111(3), 423-447.

Prodhon, C., \& Prins, C. (2014). A survey of recent research on location-routing problems. European Journal of Operational Research, 238(1), 1-17.

Rustenburg, J. W., van Houtum, G. J., \& Zijm, W. H. M. (2003). Exact and approximate analysis of multi-echelon, multi-indenture spare parts systems with commonality. In Stochastic Modeling and Optimization of Manufacturing Systems and Supply Chains (pp. 143-176). Springer US.

Seyedhosseini, S. M., Bozorgi-Amiri, A., \& Daraei, S. (2014). An Integrated Location-RoutingInventory Problem by Considering Supply Disruption. I-Business, 6(2), 29.

Sherbrooke, C. C. (1968). METRIC: A multi-echelon technique for recoverable item control. Operations Research, 16(1), 122-141.

Sherbrooke, C. C. (1986). VARI-METRIC: improved approximations for multi-indenture, multiechelon availability models. Operations Research, 34(2), 311-319.

Slay, F. M. (1984). VARI-METRIC: An approach to modelling multi-echelon resupply when the demand process is Poisson with a gamma prior. Report AF301-3, Logistic Management Institute, Washington, DC, 232.

Vincent, F. Y., Lin, S. W., Lee, W., \& Ting, C. J. (2010). A simulated annealing heuristic for the capacitated location routing problem. Computers \& Industrial Engineering, 58(2), 288-299.

Wang, C., Ma, Z., \& Li, H. (2008, October). Stochastic dynamic location-routing-inventory problem in closed-loop logistics system for reusing end-of-use products. In Intelligent Computation Technology and Automation (ICICTA), 2008 International Conference on (Vol. 2, pp. 691-695). IEEE.

Wang, Y., Cohen, M. A., \& Zheng, Y. S. (2000). A two-echelon repairable inventory system with stocking-center-dependent depot replenishment lead times. Management Science, 46(11), 14411453.

Wong, H., van Houtum, G. J., Cattrysse, D., \& Van Oudheusden, D. (2005). Simple, efficient heuristics for multi-item multi-location spare parts systems with lateral transshipments and waiting time constraints. Journal of the Operational Research Society, 56(12), 1419-1430.

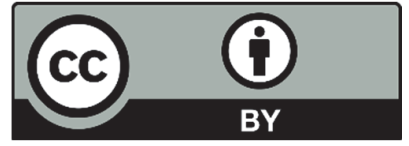

(C) 2017 by the authors; licensee Growing Science, Canada. This is an open access article distributed under the terms and conditions of the Creative Commons Attribution (CC-BY) license (http://creativecommons.org/licenses/by/4.0/). 